This is a self-archived version of an original article. This version may differ from the original in pagination and typographic details.

Author(s): Rosa, José; Lahtinen, Jouko; Julin, Jaakko; Sun, Zhipei; Lipsanen, Harri

Title: Tuning of Emission Wavelength of CaS:Eu by Addition of Oxygen Using Atomic Layer Deposition

Year: 2021

Version: Published version

Copyright: (c) 2021 by the authors. Licensee MDPI, Basel, Switzerland.

Rights: $C C B Y 4.0$

Rights url: https://creativecommons.org/licenses/by/4.0/

Please cite the original version:

Rosa, J., Lahtinen, J., Julin, J., Sun, Z., \& Lipsanen, H. (2021). Tuning of Emission Wavelength of CaS:Eu by Addition of Oxygen Using Atomic Layer Deposition. Materials, 14(20), Article 5966. https://doi.org/10.3390/ma14205966 


\title{
Tuning of Emission Wavelength of CaS:Eu by Addition of Oxygen Using Atomic Layer Deposition
}

\author{
José Rosa ${ }^{1, *}$, Jouko Lahtinen ${ }^{2}$, Jaakko Julin ${ }^{3}$, Zhipei Sun ${ }^{1}$ and Harri Lipsanen ${ }^{1, *}$ (i) \\ 1 Department of Electronics and Nanoengineering, Aalto University, P.O. Box 13500, FI-00076 Aalto, Finland; \\ zhipei.sun@aalto.fi \\ 2 Department of Applied Physics, Aalto University, P.O. Box 11000, FI-00076 Aalto, Finland; \\ jouko.lahtinen@aalto.fi \\ 3 Department of Physics, University of Jyväskylä, P.O. Box 35, FI-40014 Jyväskylä, Finland; jaakko.julin@jyu.fi \\ * Correspondence: jose.rosa@aalto.fi (J.R.); harri.lipsanen@aalto.fi (H.L.)
}

Citation: Rosa, J.; Lahtinen, J.; Julin, J.; Sun, Z.; Lipsanen, H. Tuning of Emission Wavelength of CaS:Eu by Addition of Oxygen Using Atomic Layer Deposition. Materials 2021, 14 , 5966. https://doi.org/10.3390/ ma14205966

Academic Editor:

Gueorgui Gueorguiev

Received: 12 September 2021

Accepted: 8 October 2021

Published: 11 October 2021

Publisher's Note: MDPI stays neutral with regard to jurisdictional claims in published maps and institutional affiliations.

Copyright: (c) 2021 by the authors. Licensee MDPI, Basel, Switzerland. This article is an open access article distributed under the terms and conditions of the Creative Commons Attribution (CC BY) license (https:/ / creativecommons.org/licenses/by/ $4.0 /)$.

\begin{abstract}
Atomic layer deposition (ALD) technology has unlocked new ways of manipulating the growth of inorganic materials. The fine control at the atomic level allowed by ALD technology creates the perfect conditions for the inclusion of new cationic or anionic elements of the alreadyknown materials. Consequently, novel material characteristics may arise with new functions for applications. This is especially relevant for inorganic luminescent materials where slight changes in the vicinity of the luminescent centers may originate new emission properties. Here, we studied the luminescent properties of CaS:Eu by introducing europium with oxygen ions by ALD, resulting in a novel CaS:EuO thin film. We study structural and photoluminescent properties of two different ALD deposited Eu doped $\mathrm{CaS}$ thin films: $\mathrm{Eu}$ (thd) $)_{3}$ which reacted with $\mathrm{H}_{2} \mathrm{~S}$ forming CaS:Eu phosphor, or with $\mathrm{O}_{3}$ originating a $\mathrm{CaS}: \mathrm{EuO}$ phosphor. It was found that the emission wavelength of $\mathrm{CaS}: \mathrm{EuO}$ was $625.8 \mathrm{~nm}$ whereas CaS:Eu was $647 \mathrm{~nm}$. Thus, the inclusion of $\mathrm{O}^{2-}$ ions by ALD in a CaS:Eu phosphor results in the blue-shift of $21.2 \mathrm{~nm}$. Our results show that ALD can be an effective way to introduce additional elements (e.g., anionic elements) to engineer the physical properties (e.g., inorganic phosphor emissions) for photonics and optoelectronics.
\end{abstract}

Keywords: CaS:Eu; phosphor; photoluminescence; atomic layer deposition

\section{Introduction}

The development of new luminescent materials and optoelectronic devices such as lamps, displays, lasers, solar cells and photodetectors, relies strongly on the flexibility of the used fabrication technique. The need for higher material quality and versatility in the fabrication of optoelectronic devices was one of the main motivations that lead to the birth and development of atomic layer deposition (ALD) [1,2]. As an example, in the early days of ALD, inorganic phosphors such as $\mathrm{ZnS}: \mathrm{M}(\mathrm{M}=\mathrm{Mn}, \mathrm{Tb}, \mathrm{Tm}), \mathrm{SrS}: \mathrm{M}(\mathrm{M}=\mathrm{Ce}, \mathrm{Cu}, \mathrm{Tb}$, $\mathrm{Pb}), \mathrm{CaS}: \mathrm{M}(\mathrm{M}=\mathrm{Eu}, \mathrm{Ce}, \mathrm{Tb}, \mathrm{Pb})$, were extensively researched for the development of thin film electroluminescent displays (TFEL) [3].

ALD takes a relevant role in the synthetization of inorganic phosphors. The selflimiting mechanism of ALD allows the growth of one atomic layer at the time, consequently leading to accurate control of the thin film thickness and the ability to create multilayer structures [4]. Furthermore, the meticulous inclusion of dopants can be conducted in a single fabrication run, while the host material is being grown. These effects are particularly interesting regarding the doping level control of thin film materials. Thus, they are appropriate for the fabrication of inorganic phosphors, where the doping element acts as a luminescent center. It is known that if the luminescent centers are close to each other it can lead to concentration quenching. However, using ALD, the spatial distance between the luminescent centers can be controlled. The distance is restrained by the steric hindrance effect of the ligands [5-8]. With this distribution engineering procedure, higher doping 
concentrations can be achieved in comparison to other fabrication techniques [7], which may reflect in higher luminance values.

In recent years, ALD technology has been used to explore new ways of combining atomic elements to develop materials with unorthodox characteristics. As a result, the research of single-anion (homo-anionic) compounds, such as pure metal oxides, pnictides (nitrides, arsenides, phosphides) or chalcogenides (sulfides, selenides, tellurides), has given place to a mixed anion-centered (multi-anion or hetero-anionic) compounds research [9]. Mixed anion centered materials include for example carbonitrides [10], oxyfluorides [11], oxynitrides [12], oxycarbides [13], and oxysulfides [14]. The ability to incorporate different types of anions allows to change a variety of material properties and characteristics. Electron configuration, electronegativity, size, charge and polarization of this anionic species can lead to the creation of unique structural, chemical, electronic, optical, and magnetic states. In such materials, ALD technique grants the fine-tuning between the combination of cations and multiple anions in thin films [9].

A good example of ALD multi-anion research applied to luminescent materials is a previous study on the control europium of the oxidation state in a $\mathrm{Y}_{2} \mathrm{O}_{3-\mathrm{x}} \mathrm{S}_{\mathrm{X}}$ matrix [14]. In this research, it was demonstrated that the oxidation state of Eu luminescent center could be changed by the introduction of Eu atoms with an ALD sub cycle of two different anion precursors: either $\mathrm{H}_{2} \mathrm{~S}$ or $\mathrm{O}_{3}$. The distinct oxidation states of the luminescent center led to different emission spectrums of the $\mathrm{Y}_{2} \mathrm{O}_{3-\mathrm{x}} \mathrm{S}_{\mathrm{X}}$ :Eu phosphor.

Inspired by the previous report, we continue to explore the ALD fabrication potential. More specifically, the ability of shifting the peak emission of calcium sulfide doped with europium (CaS:Eu), a well-known red emitting inorganic phosphor material. CaS:Eu luminescent characteristics have been widely studied and used in a variety of applications such as, medical imaging [15,16], cell labeling [17], white-light-emitting diodes [18,19] and electroluminescent devices [20-23]. The red emission in CaS:Eu is originated from the Eu divalent state of ionization $\left(\mathrm{Eu}^{2+}\right)$ and its broad emission is caused by electron transition from the lower $4 \mathrm{f}^{6} 5 \mathrm{~d}^{1}$ state to the $4 \mathrm{f}^{7}$ ground state [24]. This transition in a CaS host originates an emission with wavelength range from 600 to $750 \mathrm{~nm}$ and with a peak emission at $650 \mathrm{~nm}$.

In the present article, it is shown that the peak emission of CaS:Eu can be shifted using ALD method. The shift can occur by introducing localized oxygen atoms in the phosphor matrix. Hence, the inorganic phosphor emission was compared between two different structures, (1) pure CaS:Eu, where $\mathrm{Eu}$ is exposed to $\mathrm{H}_{2} \mathrm{~S}$ reducing gas, and (2) $\mathrm{CaS}: \mathrm{EuO}$, where $\mathrm{Eu}$ in exposed to $\mathrm{O}_{3}$ oxidating gas during the material growth. In comparison to the CaS:Eu phosphor, $\mathrm{CaS}: \mathrm{EuO}$ reveals a red peak emission towards shorter wavelengths. Similar tuning effects of the CaS:Eu emission has been previously reported by adding alkaline earth metals such as strontium [25,26], magnesium and barium to the reaction mixture [27]. However, we present a study where the tuning is performed by adding oxygen anions reinforcing the idea that ALD can be used to modify the vicinity of the dopant elements. These materials fabricated by ALD can thus be used for applications where the fine color tuning is advantageous such as: red electroluminescent devices [20-23,28], white-light-emitting diodes [18,19] solar cells [29], and lasers [6,8,30].

\section{Materials and Methods}

Film growth was performed using atomic layer deposition in a Beneq TFS-200 ALDreactor (Beneq Oy, Espoo, Finland). The reactor pressure was around 2 mbar during the process and the temperature was kept at $300{ }^{\circ} \mathrm{C}$. $\mathrm{N}_{2}$ was used as a carrier and purge gas. All films were grown on (100)-Si substrates coated with $10 \mathrm{~nm}$ of $\mathrm{Al}_{2} \mathrm{O}_{3}$ thin film. Trimethylaluminum (TMA, $\left.\mathrm{Al}\left(\mathrm{CH}_{3}\right)_{3}\right)(98 \%$, Strem Chemicals UK Ltd., Cambridge, UK) and $\mathrm{H}_{2} \mathrm{O}$ were used to grow $\mathrm{Al}_{2} \mathrm{O}_{3}$ coating film. All CaS based thin films were grown using $\beta$-diketonate precursors: $\mathrm{Ca}(\text { thd })_{2}\left(99 \%\right.$. Volatec, Porvoo, Finland) and $\mathrm{Eu}(\text { thd })_{3}(99.5 \%$, Intatrade, Anhalt-Bitterfeld Germany) (THD = 2,2,6,6-tetramethyl-3,5-heptanedionate). $\mathrm{Ca}$ (thd $)_{2}$ was kept at $205^{\circ} \mathrm{C}$ while Eu(thd $)_{3}$ was kept at $185^{\circ} \mathrm{C}$ with a vapor pressure of 
$133 \mathrm{~Pa}$ [31]. $\mathrm{Ca}(\text { thd })_{2}$ vapor pressure is unknown in literature. CaS matrix was formed by reacting $\mathrm{Ca}$ (thd $)_{2}$ with $\mathrm{H}_{2} \mathrm{~S}$ using 350 pulses of each chemical. After the first 350 pulses, $\mathrm{Eu}$ (thd $)_{3}$ was introduced as a doping agent by pulsing either $\mathrm{H}_{2} \mathrm{~S}$ or $\mathrm{O}_{3}$. Two cycles of $\mathrm{Eu}$ (thd $)_{3}$ followed by $\mathrm{H}_{2} \mathrm{~S}$ were used in one of the samples. A sequence of three $\mathrm{O}_{3}$ pulses intercalated by two pulses of $\mathrm{Eu}(\mathrm{thd})_{3}$ were used in the other sample. A schematic representation of the doping sequences used in the two samples can be seen in Figure 1. Both phosphor layers were grown using 6 layers of $\mathrm{CaS}$ intercalated by five Eu layers, resulting in approximately $100 \mathrm{~nm}$ thin film. Finally, another $10 \mathrm{~nm}$ layer of $\mathrm{Al}_{2} \mathrm{O}_{3}$ was used to coat the europium doped $\mathrm{CaS}$ thin films. Thus, two different samples were studied in this work: $\mathrm{Al}_{2} \mathrm{O}_{3} / \mathrm{CaS}: \mathrm{Eu} / \mathrm{Al}_{2} \mathrm{O}_{3} / \mathrm{Si}$ and $\mathrm{Al}_{2} \mathrm{O}_{3} / \mathrm{CaS}: \mathrm{EuO} / \mathrm{Al}_{2} \mathrm{O}_{3} / \mathrm{Si}$, denominated from now on as $\mathrm{CaS}: \mathrm{Eu}$ and $\mathrm{CaS}: \mathrm{EuO}$, respectively. Table 1 summarizes the pulsing sequence, pulse and purge times, and the respective number of cycles.

Table 1. Pulsing sequences and respective pulsing times, number of cycles per layer for CaS:Eu and CaS:EuO phosphor layers.

\begin{tabular}{cccc}
\hline Sample & Pulsing Sequence & Pulsing Time (s) & $\begin{array}{c}\text { Number of } \\
\text { Cycles per Layer }\end{array}$ \\
\hline CaS:Eu & $\mathrm{Ca}(\mathrm{Thd})_{2} / \mathrm{N}_{2} / \mathrm{H}_{2} \mathrm{~S} / \mathrm{N}_{2}$ & $2 / 5 / 0.2 / 3$ & 350 \\
& $\mathrm{Eu}(\mathrm{Thd})_{3} / \mathrm{N}_{2} / \mathrm{H}_{2} \mathrm{~S} / \mathrm{N}_{2}$ & $3 / 7 / 0.2 / 3$ & 2 \\
\hline $\mathrm{CaS}: \mathrm{EuO}$ & $\mathrm{Ca}(\mathrm{Thd})_{2} / \mathrm{N}_{2} / \mathrm{H}_{2} \mathrm{~S}_{2} / \mathrm{N}_{2}$ & $2 / 5 / 0.2 / 3$ & 350 \\
& $\mathrm{O}_{3} / \mathrm{N}_{2} / \mathrm{Eu}(\mathrm{Thd})_{3} / \mathrm{N}_{2} / \mathrm{O}_{3} / \mathrm{N}_{2} /$ & $3 / 5 / 3 / 7 / 3 / 5 / 3 / 7 / 3 / 5$ & 1 \\
& $\mathrm{Eu}(\mathrm{Thd})_{3} / \mathrm{N}_{2} / \mathrm{O}_{3} / \mathrm{N}_{2}$ & & \\
\hline
\end{tabular}

The growth per cycle (GPC) of $\mathrm{Al}_{2} \mathrm{O}_{3}, \mathrm{CaS}, \mathrm{Eu}_{2} \mathrm{O}_{3}$ was determined individually by using a SE400adv ellipsometer (SENTECH Instruments $\mathrm{GmbH}$, Berlin, Germany) with a $633 \mathrm{~nm}$ wavelength at $70^{\circ}$ angle of incidence. The crystallinity of europium doped CaS thin films was investigated by X-ray diffraction (XRD) using the $\mathrm{Cu} K \alpha$ line in a Rigaku SmartLab (Rigaku Europe SE, Neu-Isenburg, Germany) high-resolution X-ray diffractometer. Data acquired by the XRD were analyzed using the HighScore Plus 4.6 (PANalytical B.V., Almelo, The Netherlands). The X-ray photoelectron spectroscopy (XPS) measurements were made using Kratos Axis Ultra system (Kratos Analytical Ltd., Manchester, UK), equipped with a monochromatic Al K $\alpha$ X-ray source. All measurements were performed with $0.3 \mathrm{~mm} \times 0.7 \mathrm{~mm}$ analysis area. The wide scans were performed with $80 \mathrm{eV}$ pass energy and $1 \mathrm{eV}$ energy step, and the high-resolution scans were performed with $40 \mathrm{eV}$ pass energy at $0.1 \mathrm{eV}$ steps. Eu doped $\mathrm{CaS}$ samples were analyzed with elastic recoil detection analysis (ERDA) using a $13.6 \mathrm{MeV}^{63} \mathrm{Cu}^{7+}$ ion beam. The investigated area was approximately $2 \times 2 \mathrm{~mm}^{2}$. The measurement was carried out with a $70^{\circ}$ angle between the sample normal and beam, whereas the scattering angle was $40.6^{\circ}$. Time-of-flight-energy (ToF-E) telescope was used to detect the recoiling atoms from the sample. Photoluminescence (PL) emission of Eu doped CaS thin films was measured with a Hitachi F-7100 Fluorescence Spectrophotometer (Hitachi High-Tech Analytical Science Ltd., Abingdon, UK) equipped with a $150 \mathrm{~W}$ xenon lamp. Measurements were performed at room temperature with a photomultiplier tube voltage of $400 \mathrm{~V}$, with a bandwidth of $10 \mathrm{~nm}$. 
(0)

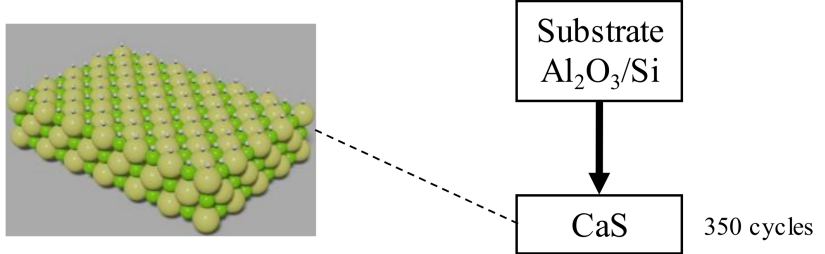

(A1)
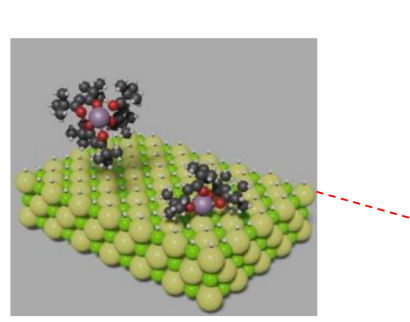

(A2)
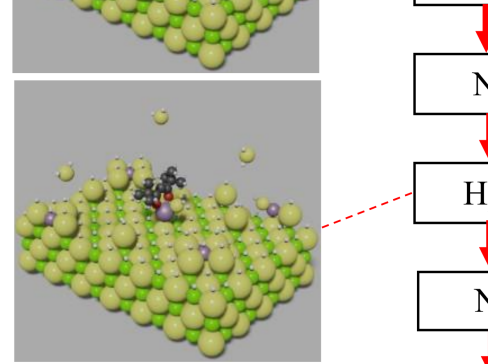

$\mathrm{CaS}: \mathrm{Eu}$

$\mathrm{CaS}: \mathrm{EuO}$
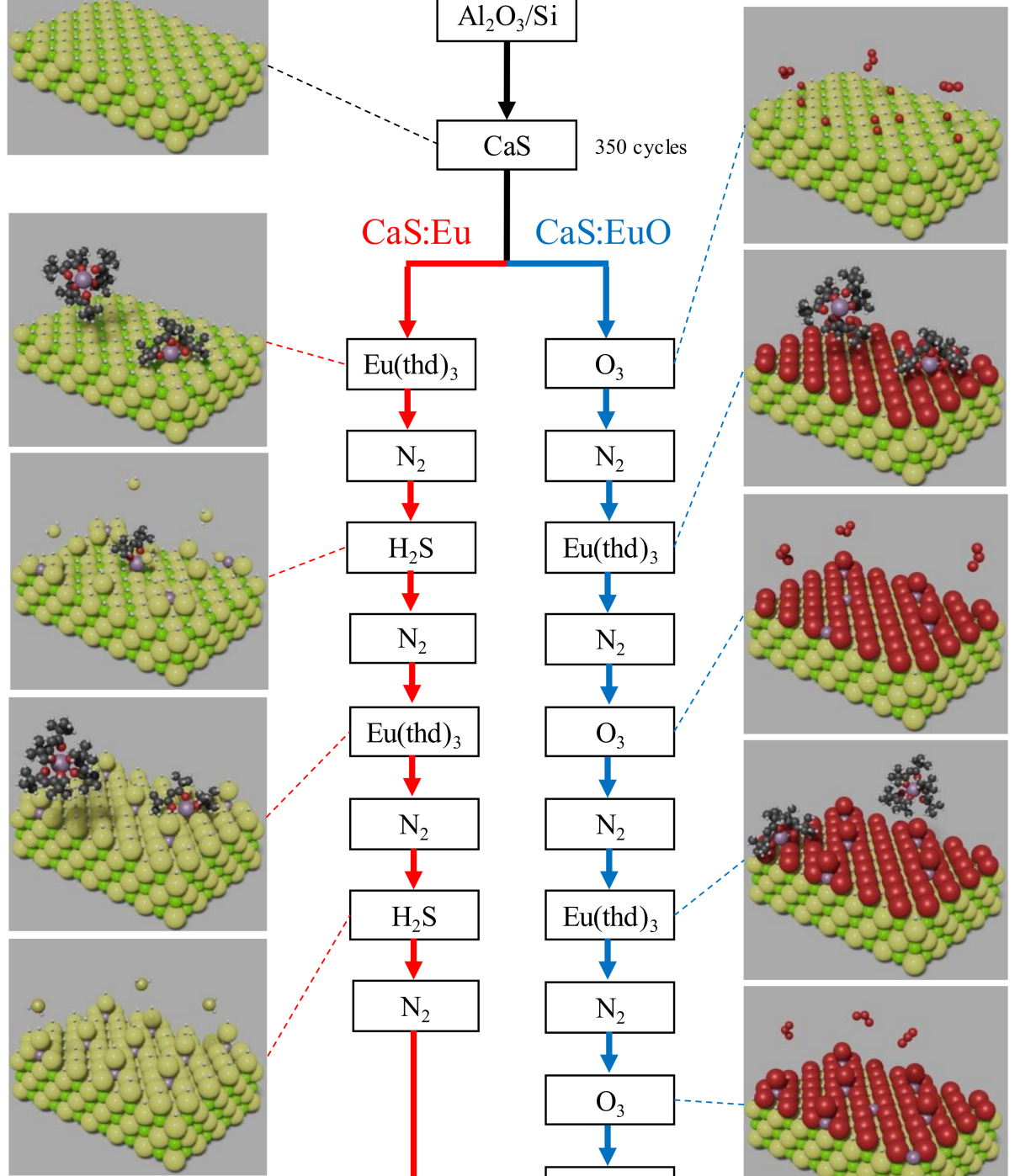

\section{(A3)}

$$
\text { (A4) }
$$
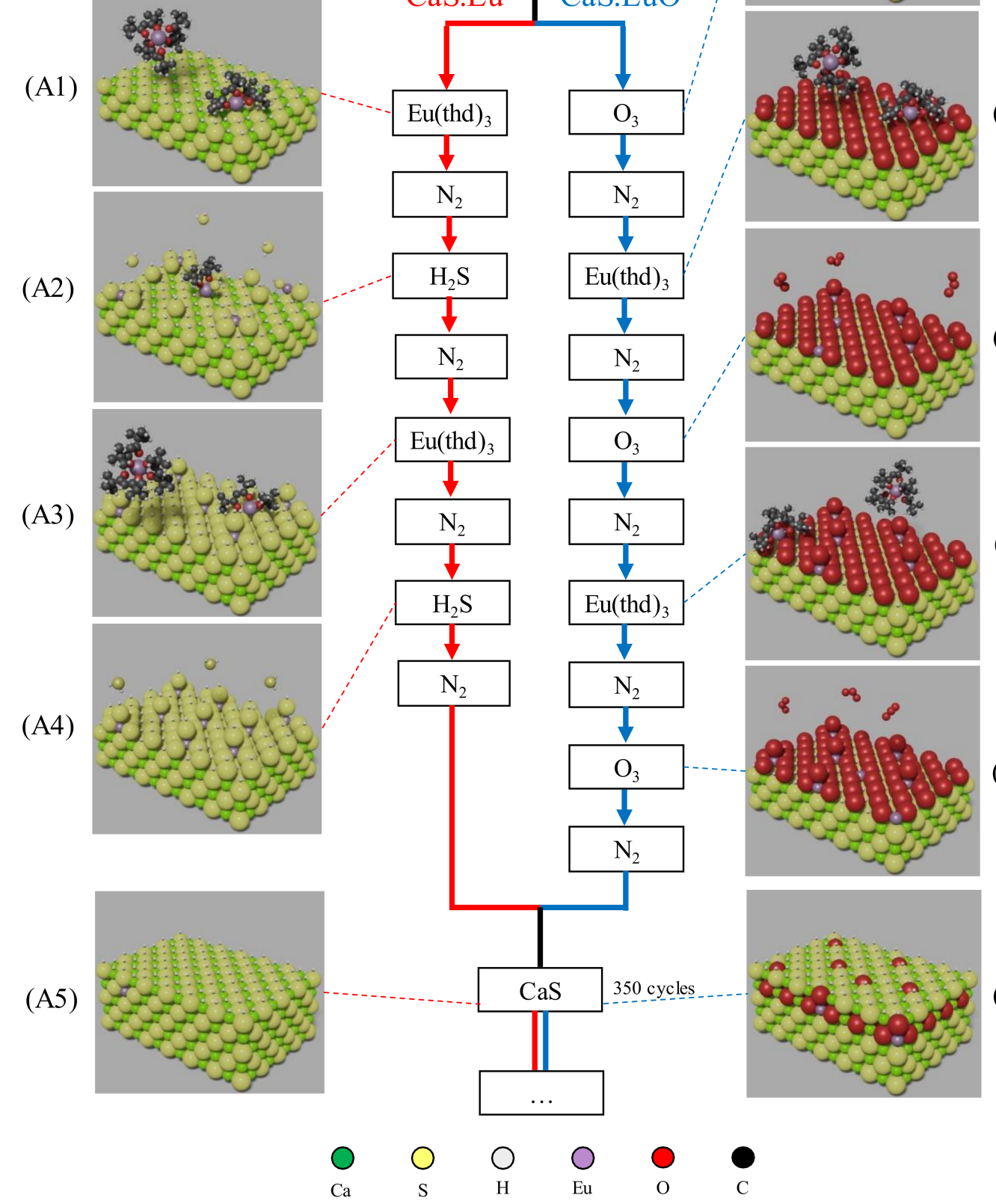

\section{(B2)}

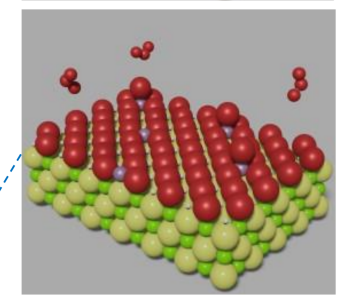

(B3)



(B4)

(B5)
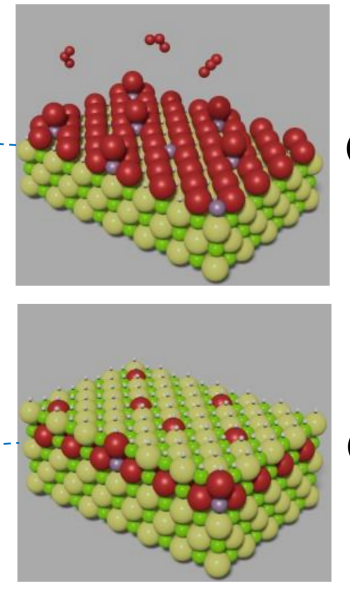

(B6)

Figure 1. Schematic of ALD doping sequence used in CaS:Eu and CaS:EuO samples. (0) Top layers of CaS matrix. Red track represents the doping sequence in CaS:Eu sample including: (A1) Eu(thd) ${ }_{3}$ pulsing on CaS layer, (A2) $\mathrm{H}_{2} \mathrm{~S}$ pulsing after nitrogen purge, (A3) second $\mathrm{Eu}(\text { thd })_{3}$ pulsing after purge, (A4) $\mathrm{H}_{2} \mathrm{~S}$ pulsing after nitrogen purge and (A5) CaS monolayer after the doping sequence. Blue track represents the doping sequence in CaS:EuO sample including: (B1) $\mathrm{O}_{3}$ pulse on CaS layer, (B2) Eu(thd) $)_{3}$ pulsing after purge, (B3) second $\mathrm{O}_{3}$ pulsing after nitrogen purge, (B4) second Eu(thd) $)_{3}$ pulsing after purge, (B5) third $\mathrm{O}_{3}$ pulsing after nitrogen purge and (B6) CaS monolayer after the doping sequence. Atomic elements are represented with the following colors: $(\mathrm{Ca})$ green, $(\mathrm{S})$ yellow, $(\mathrm{H})$ gray, $(\mathrm{Eu})$ lavender, $(\mathrm{O})$ red and $(\mathrm{C})$ black. 


\section{Results}

\subsection{Crystallinity}

Figure 2 illustrates grazing incidence XRD patterns for $\mathrm{CaS}: \mathrm{Eu}$ and $\mathrm{CaS}: \mathrm{EuO}$ thin films measured between $15^{\circ}$ and $65^{\circ}$. XRD patterns were carried out with an incidence angle of $2^{\circ}$. The grazing incident XRD data for both thin films show a main polycrystalline phase

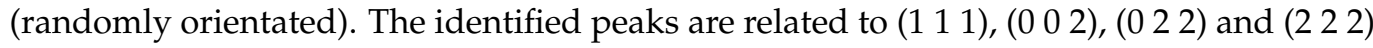
reflections. The peak position and the order of peak intensity are similar to the one reported by cross-reference COD:96-900-8607 [32]. Thus, indicating that CaS:Eu and CaS:EuO have a cubic structure with $\mathrm{Fm} \overline{3} \mathrm{~m}$ space group. The lattice parameter was determined to be $\mathrm{a}=5.68 \AA$ and $\mathrm{a}=5.69 \AA$ for CaS:Eu and CaS:EuO, respectively. Furthermore, CaS:Eu shows a higher level of crystallinity compared to CaS:EuO thin film.

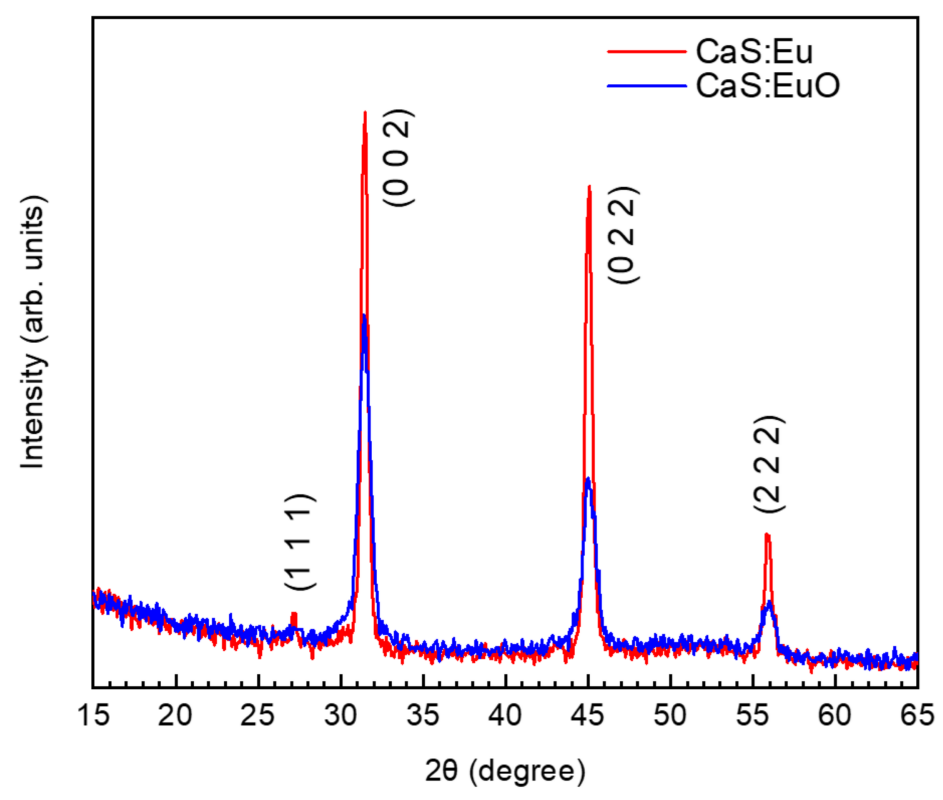

Figure 2. Grazing incidence XRD of CaS:Eu and CaS:EuO samples.

\subsection{Chemical Analysis}

XPS was performed on both CaS:Eu and CaS:EuO samples. We used argon ion etching to remove the $10 \mathrm{~nm} \mathrm{Al}_{2} \mathrm{O}_{3}$ top coating layer prior to detailed analysis of the materials. The removal of the oxide was followed by XPS measurements after $100 \mathrm{~s}, 200 \mathrm{~s}, 400 \mathrm{~s}, 600 \mathrm{~s}$ and $1000 \mathrm{~s}$ of ion etching. In the CaS:Eu sample the $\mathrm{Al} 2 \mathrm{p}$ peak disappeared after $600 \mathrm{~s}$ whereas in the CaS:EuO sample the $\mathrm{Al} 2 \mathrm{p}$ intensity decreased by a factor of four after $1000 \mathrm{~s}$.

The S 2p spectra of CaS:Eu and CaS:EuO in Figure 3a, show a typical doublet with $1.18 \mathrm{eV}$ separation. The $\mathrm{S} 2 \mathrm{p}$ binding energy of $160.7 \mathrm{eV}$ indicates the presence of sulfides, whereas the sulfate component around $169 \mathrm{eV}$ is missing [33]. The Ca $2 \mathrm{p}$ spectra of both samples are illustrated in Figure $3 \mathrm{~b}$. The CaS:Eu spectrum shows a typical doublet with $3.55 \mathrm{eV}$ separation. The $\mathrm{Ca} 2 \mathrm{p}_{3 / 2}$ binding energy of $346.4 \mathrm{eV}$ corresponds to $\mathrm{CaS}$ or $\mathrm{CaO}$. In the $\mathrm{CaS}: \mathrm{EuO}$ sample, an additional component related to the $\mathrm{CaCO}_{3}$ or $\mathrm{CaSO}_{4}$ is seen at $347.9 \mathrm{eV}$, with a peak area corresponding to $20 \%$ of the total $\mathrm{Ca}$. As there is no sulphate peak in the $\mathrm{S} 2 \mathrm{p}$ spectra, we call this peak $\mathrm{CaCO}_{3}$ although the binding energy would better fit to $348.0 \mathrm{eV}$ of $\mathrm{CaSO}_{4}$ than $(347.1 \pm 0.3) \mathrm{eV}$ of $\mathrm{CaCO}_{3}$ [33]. The fitting also includes a satellite peak above $353 \mathrm{eV}$ in both samples. Figure $3 \mathrm{c}$ shows the measured $\mathrm{O} 1 \mathrm{~s}$ spectra. There is only one peak appearing at $531.6 \mathrm{eV}$ in both samples, indicating similar oxygen. However, the $\mathrm{O} 1 \mathrm{~s}$ signal from CaS:EuO indicates 42 at- $\%$ of oxygen whereas that of the CaS:Eu only 10 at- $\%$. Figure 3d shows the C 1s spectra. The CaS:Eu sample does not contain carbon. In the CaS:EuO sample a small C 1s peak around $292 \mathrm{eV}$ is seen. This peak can be related to $\mathrm{CO}_{3}$ groups. There might also be some structure above the noise level around $286 \mathrm{eV}$. The amount of carbon in the CaS:EuO sample is below 2 at- $\%$. 

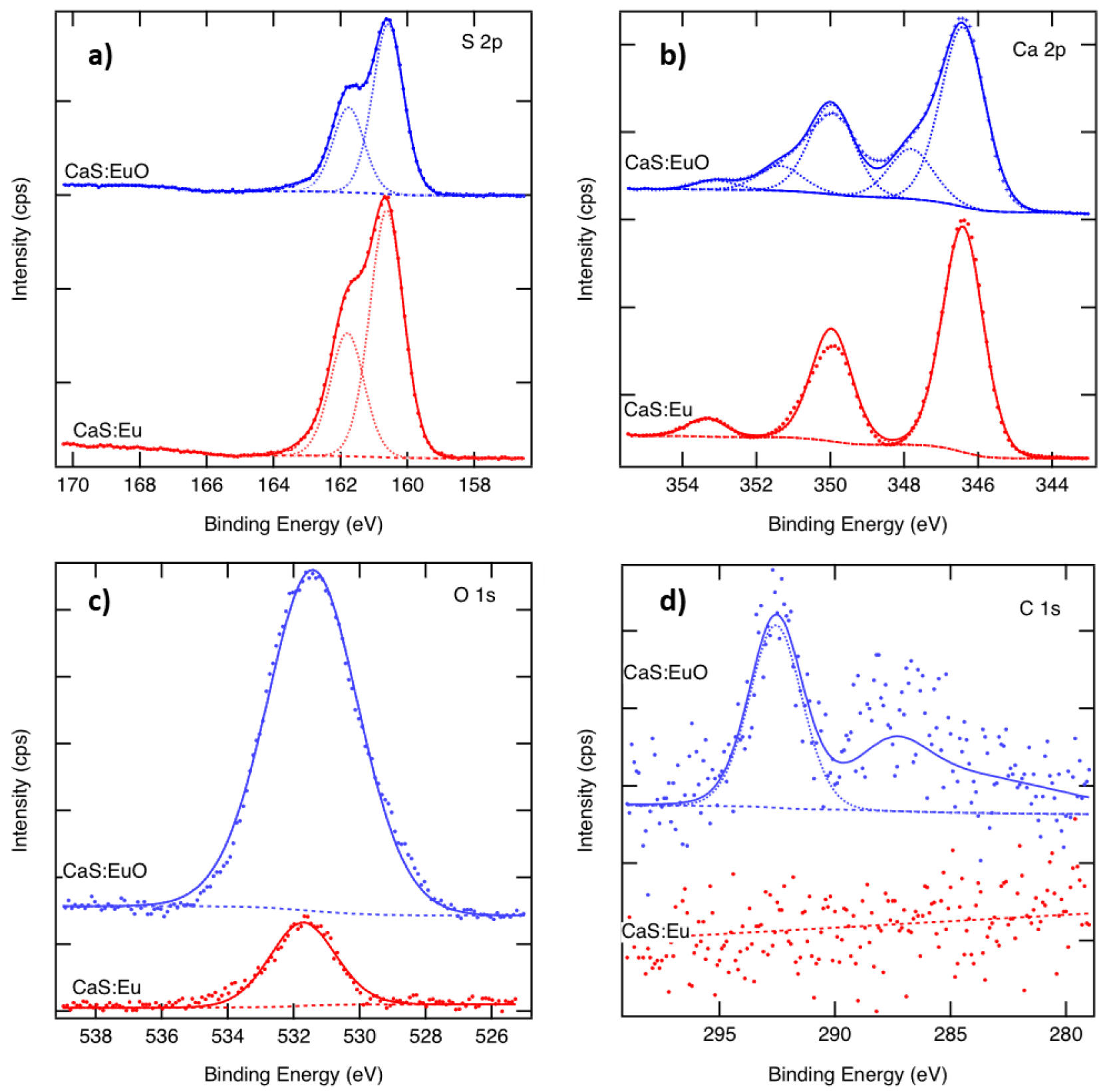

Figure 3. Measured and fitted (a) S 2p, (b) Ca 2p and (c) O 1s and (d) C 1s spectra of CaS:Eu and CaS:EuO samples.

Figure 4 illustrate the Eu 3d core levels of $\mathrm{CaS}: \mathrm{Eu}$ and $\mathrm{CaS}: \mathrm{EuO}$, respectively. Eu ${ }^{3+}$ and $\mathrm{Eu}^{2+}$ oxidation states can be identified in both samples if we accept binding energies $1134.4 \mathrm{eV}$ and $1124.7 \mathrm{eV}$ for the components [34]. However, the data are noisy despite of the long measurement time used. We can estimate that the $\mathrm{Eu}^{3+} / \mathrm{Eu}^{2+}$ ratio is approximately 5/2 in CaS:Eu whereas in CaS:EuO it is close to 6/1. 


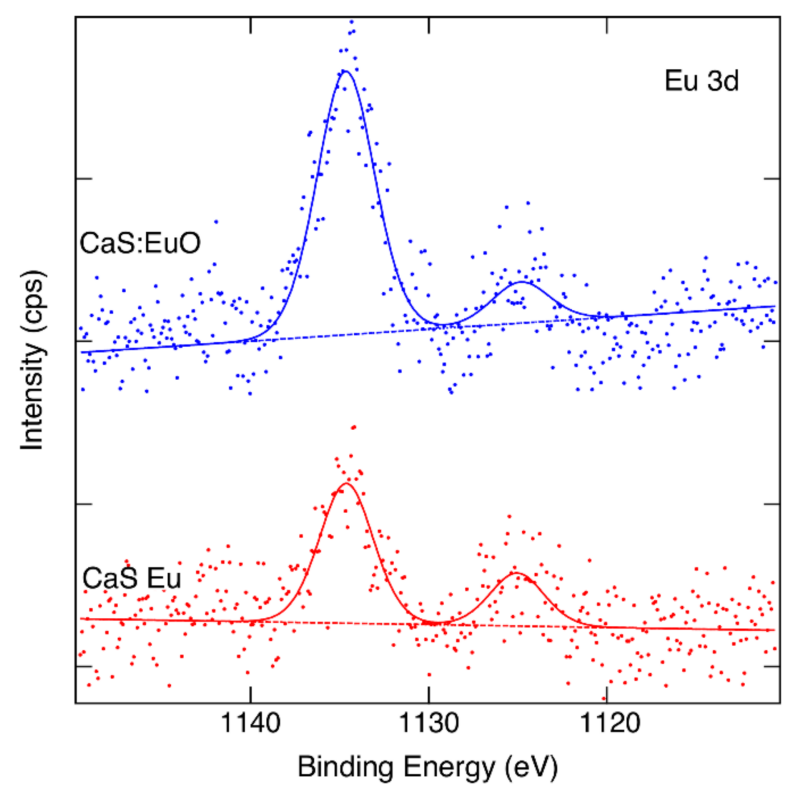

Figure 4. Measured and fitted Eu 3d spectra of CaS:Eu and CaS:EuO samples.

Figure $5 \mathrm{a}, \mathrm{b}$ illustrates the elemental depth profile obtained by ToF-ERDA measurements of $\mathrm{CaS}: \mathrm{Eu}$ and $\mathrm{CaS}: \mathrm{EuO}$ samples, respectively. The depth resolution degrades deeper in the sample due to energy loss straggling. Therefore, the elemental composition of both europium doped $\mathrm{CaS}$ layers was analyzed by selecting an interval representative of the film bulk, with no $\mathrm{Al}$ and high concentration of $\mathrm{Ca}$ and $\mathrm{S}$. The vertical lines in the depth profile plots indicate the depth range from which the averages in Table 2 are calculated.
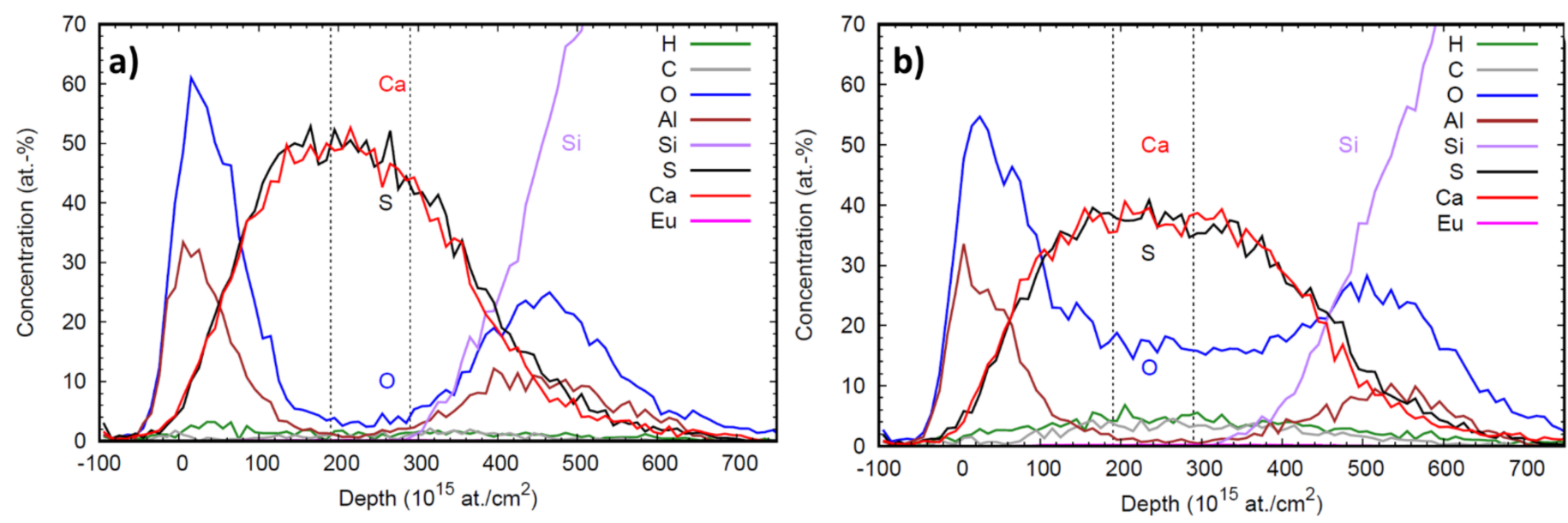

Figure 5. Depth profile of (a) CaS:Eu and (b) CaS:EuO samples. Dashed vertical lines indicate the depth range used for elemental compositional analysis.

Table 2. Elemental composition of the CaS:Eu and CaS:EuO samples measured with ToF-ERDA.

\begin{tabular}{ccccccc}
\hline Sample & $\begin{array}{c}\mathbf{H} \\
\text { (at. \%) }\end{array}$ & $\begin{array}{c}\text { C } \\
\text { (at. \%) }\end{array}$ & $\begin{array}{c}\text { O } \\
\text { (at. \%) }\end{array}$ & $\begin{array}{c}\text { S } \\
\text { (at. \%) }\end{array}$ & $\begin{array}{c}\text { Ca } \\
\text { (at. \%) }\end{array}$ & $\begin{array}{c}\text { Eu } \\
\text { (at. \%) }\end{array}$ \\
\hline $\mathrm{CaS}: \mathrm{Eu}$ & $1.2 \pm 0.2$ & $0.8 \pm 0.3$ & $3.2 \pm 0.3$ & $47.7 \pm 0.5$ & $47.0 \pm 0.5$ & $0.13 \pm 0.02$ \\
$\mathrm{CaS}: \mathrm{EuO}$ & $4.7 \pm 0.3$ & $3.4 \pm 0.3$ & $16.8 \pm 0.5$ & $37.5 \pm 0.5$ & $37.4 \pm 0.5$ & $0.17 \pm 0.02$ \\
\hline
\end{tabular}

Table 2 shows a comparison between the element composition of CaS:Eu and CaS:EuO layers. In both films, the atomic percentages of $\mathrm{S}$ and $\mathrm{Ca}$ are approximately the same, demonstrating that $\mathrm{CaS}$ is present with a stoichiometry of 1:1. The doping level is higher 
for samples where Eu is grown on CaS with ozone. As expected, the level of oxygen present in the doped layer is higher when ozone is used to introduce $\mathrm{Eu}(\mathrm{thd})_{3}$. However, in the sample where no ozone was used there is still a low concentration of oxygen impurities. Both $\mathrm{H}$ and $\mathrm{C}$ contamination levels were higher in the $\mathrm{CaS}: \mathrm{EuO}$ sample.

\subsection{Photoluminescence}

The normalized PL spectra were plotted in Figure 6a to facilitate the comparison between the maximum emission wavelength of $\mathrm{CaS}: \mathrm{Eu}$ and $\mathrm{CaS}: \mathrm{EuO}$ samples. Both photoluminescent emission spectra were measured between 600 and $700 \mathrm{~nm}$ and excited with approximated wavelengths values correspondent to the maximum emission intensity. The CaS:Eu sample has a maximum emission value of $647 \mathrm{~nm}$, when excited with a wavelength of $225 \mathrm{~nm}$. The maximum emission is related to the $\mathrm{Eu}^{2+}$ ion Laporte allowed transition, from $4 \mathrm{f}^{6} 5 \mathrm{~d}^{1}$ to the $4 \mathrm{f}^{7}\left({ }^{8} \mathrm{~S}_{7 / 2}\right)$, characteristic of CaS:Eu ${ }^{2+}$ materials [24]. In addition, $\mathrm{CaS}: \mathrm{EuO}$ sample shows a maximum peak emission of $625.8 \mathrm{~nm}$, for an excitation wavelength of $230 \mathrm{~nm}$. The PL measurements were carried out in three different CaS:EuO samples for reproducibility proposes. All tree samples showed similar behavior.


Figure 6. (a) Normalized emission spectra and (b) excitation spectra from CaS:Eu and CaS:EuO, measured at room temperature.

Furthermore, photoluminescent excitation (PLE) spectra in Figure $6 \mathrm{~b}$ were registered by monitoring the emission at $640 \mathrm{~nm}$ and $630 \mathrm{~nm}$ for CaS:Eu and CaS:EuO samples, respectively. All samples show a broad excitation band between 200 and $300 \mathrm{~nm}$, which can be associated with the $\mathrm{Eu}^{2+} 4 \mathrm{f}^{7}\left({ }^{8} \mathrm{~S}_{7 / 2}\right) \rightarrow 4 \mathrm{f}^{6} 5 \mathrm{~d}^{1}\left[\mathrm{E}_{\mathrm{g}}\right]$ and valence-to-conduction band transitions. Whereas the low intensity excitation band in CaS:Eu sample from 400 to $550 \mathrm{~nm}$ is related to $\mathrm{Eu}^{2+} 4 \mathrm{f}^{7} \rightarrow 4 \mathrm{f}^{6} 5 \mathrm{~d}^{1}\left[\mathrm{t}_{2 \mathrm{~g}}\right.$ ] transition [35]. This transition is believed to have too low intensity to be detected in $\mathrm{CaS}: \mathrm{EuO}$ sample, therefore it was not used to excite the samples.

A summary of Figure $6 a, b$ is presented in Table 3, which include the excitation and absorption wavelength; excitation and emission peak; and respective intensities. In Table 3, it is clear that CaS:Eu sample has higher intensities in comparison to CaS:EuO sample, regarding excitation and emission peaks. 
Table 3. Summary of the CaS:Eu and CaS:EuO emission and excitation data acquired from the photoluminescent measurements.

\begin{tabular}{ccccccc}
\hline Sample & $\begin{array}{c}\text { Excitation } \\
\text { Wavelength } \\
\text { [nm] }\end{array}$ & $\begin{array}{c}\text { Peak } \\
\text { Emission } \\
\text { [nm] }\end{array}$ & $\begin{array}{c}\text { Intensity } \\
\text { (arb. un.) }\end{array}$ & $\begin{array}{c}\text { Emission } \\
\text { Wavelength } \\
\text { [nm] }\end{array}$ & $\begin{array}{c}\text { Peak } \\
\text { Excitation } \\
\text { [nm] }\end{array}$ & $\begin{array}{c}\text { Intensity } \\
\text { (arb. un.) }\end{array}$ \\
\hline $\mathrm{CaS}: \mathrm{Eu}$ & 225 & 647 & 93.61 & 640 & 223.6 & 89.17 \\
$\mathrm{CaS}: \mathrm{EuO}$ & 230 & 625.8 & 19.87 & 630 & 227.2 & 20.49 \\
\hline
\end{tabular}

\section{Discussion}

With the data acquired from XPS it is possible to assume that the Al from the top coating layer can be measured until $600 \mathrm{~s}$ of argon sputtering, in CaS:Eu sample. Thus, leading to the conclusion that beyond the $600 \mathrm{~s}$ etching step, a nearly pure CaS:Eu layer can be found. Faint traces of oxygen can still be analyzed within the europium doped $\mathrm{CaS}$ layer. These traces of oxygen could originate from the $\mathrm{O}$ diffusion of the $\mathrm{Al}_{2} \mathrm{O}_{3}$ top coating layer into the CaS:Eu layer. In this case, the oxygen contamination can occur due to the slow ALD fabrication process at $300^{\circ} \mathrm{C}$. Additionally, due to the high Ca affinity towards oxygen atoms, there is the possibility of $\mathrm{O}$ present in the $\beta$-diketonate molecule to be adsorbed on the $\mathrm{CaS}$ surface, upon $\mathrm{Eu}(\text { thd })_{3}$ and $\mathrm{H}_{2} \mathrm{~S}$ reaction. The same oxygen contamination can be visualized in the ToF-ERDA analysis, see Table 2. As expected, the presence of oxygen in $\mathrm{CaS}: \mathrm{EuO}$ sample can be identified clearly after the $600 \mathrm{~s}$ due to the intentional introduction of $\mathrm{O}$ atoms. XPS analysis of sulfur species revealed that sulfur is detected in form of sulfide and no sulfates are present in the phosphor layer.

Furthermore, the results from XPS and ToF-ERDA show higher level of carbon content within the $\mathrm{CaS}: \mathrm{EuO}$ sample. These data are supported by the detection of $\mathrm{CaCO}_{3}$ component in Figure $3 \mathrm{~b}$ and higher carbon concentration shown in Table 2. The carbon contamination in $\mathrm{CaS}: \mathrm{EuO}$ could be explained by the reaction between ozone and the $\beta$-diketonate precursor $\left(\mathrm{Eu}(\mathrm{thd})_{3}\right)$, which is known to originate carbonates in the films [14]. Additionally, the ToF-ERDA analysis revealed a lower hydrogen presence in CaS:Eu, which indicates the excellent reactivity between $\mathrm{Ca}(\text { thd })_{2}$ and $\mathrm{Eu}(\text { thd })_{3}$ with $\mathrm{H}_{2} \mathrm{~S}$. These efficient surface reactions are responsible to effectively remove lighter species, such as $\mathrm{H}$ [36]. In contrast, higher levels of carbon and hydrogen contamination in $\mathrm{CaS}: \mathrm{EuO}$ sample can be correlated with the lower reactivity of $\mathrm{O}_{3}$ species with $\mathrm{Ca}(\mathrm{thd})_{2}$ and $\mathrm{Eu}(\mathrm{thd})_{3}$, in comparison to $\mathrm{H}_{2} \mathrm{~S}$. Moreover, the intentional inclusion of oxygen atoms into the europium doped CaS layer may be the major responsible factor for the lower level of crystallinity. The presence of $\mathrm{O}^{2-}$ can cause distortions in the CaS crystal lattice leading to structural defects. Nonetheless, the crystal structure of $\mathrm{CaS}: \mathrm{EuO}$ is still similar to $\mathrm{CaS}: \mathrm{Eu}$ and no traces of $\mathrm{CaO}$ or $\mathrm{CaSO}_{x}$ polycrystalline phases are identified.

It was found that the oxidation level ratio of $\mathrm{Eu}^{3+} / \mathrm{Eu}^{2+}$ is higher in the $\mathrm{CaS}: \mathrm{EuO}$ samples. The higher $\mathrm{Eu}^{3+}$ ion presence correlates with the presence of $\mathrm{O}^{2-}$ ions, which is expected since Eu tends to oxidize to its trivalent form whenever enough oxygen atoms are available. Furthermore, the europium doping level was revealed to be slightly higher when $\mathrm{Eu}(\mathrm{thd})^{3}$ was grown on the CaS layer with ozone instead of $\mathrm{H}_{2} \mathrm{~S}$. This difference in the doping level may be explained by the facilitated introduction of Eu atoms when there is a monolayer of oxygen present in the CaS surface. Oxygen has higher electronegativity than sulfur and thus increases the probability of Eu adsorption. Note that, Eu(thd) $)_{3}$ is pulsed into the ALD reactor chamber after an $\mathrm{O}_{3}$ pulse. In a previous study it was stated that Eu may be more reactive towards the $\mathrm{H}_{2} \mathrm{~S}$ in comparison to ozone, and thus increasing the doping level [14]. However, in the present study, the surface has an oxygen monolayer instead of a sulfur monolayer, prior to the $\mathrm{Eu}(\mathrm{thd})_{3}$ pulse. The oxygen presence in the surface may be a determinant factor for the Eu growth rate as a dopant, as it may increase the adsorption of $\mathrm{Eu}(\text { thd })_{3}$.

The different emission wavelengths of $\mathrm{CaS}: \mathrm{Eu}$ and $\mathrm{CaS}: \mathrm{EuO}$ samples can be explained by the presence of $\mathrm{O}^{2-}$ ion in the phosphor layer. It is probable that $\mathrm{O}^{2-}$ ion inclusion originated structural defects in the CaS structure. This can be concluded due to the lower 
intensity of the PL emission in the CaS:EuO sample, since certain defects may decrease luminance. Additionally, the defects may have distorted the crystal structure which led to a larger lattice constant, assuming a value of $5.69 \AA$ instead of $5.68 \AA$ in the presence of $\mathrm{O}^{2-}$ ions. The larger lattice constant may indicate that the distance between $\mathrm{Eu}^{2+}$ cations and the anions increase. The larger distance between $\mathrm{Eu}^{2+}$ cations and the anions lead to a decrease in the crystal-field strength $[25,26]$. Therefore, the addition of a $\mathrm{O}^{2-}$ ion originates a decrease in the energy difference between $t_{2 g}$ and the $E_{g}$ states of the $4 f^{6} 5 d^{1}$ electronic configuration, thus leading to blue-shifted emission. Figure 7 illustrates a schematic of $\mathrm{Eu}^{2+}$ energy level as function of the crystal-field. Several factors may explain the lower emission intensity of the $\mathrm{CaS}: \mathrm{EuO}$ sample in comparison to $\mathrm{CaS}: \mathrm{Eu}$, such as slightly lower Eu concentration and lower crystallinity.



Figure 7. Schematic energy diagram of $\mathrm{Eu}^{2+} 5 \mathrm{~d}$ level splitting as function of crystal-field strength in $\mathrm{CaS}: \mathrm{Eu}$ and $\mathrm{CaS}: \mathrm{EuO}$ samples.

\section{Conclusions}

In this work, two samples of Eu doped CaS phosphors were grown by ALD. Structural, chemical, compositional and emission properties of both samples were correlated with the fabrication conditions. XRD analysis shows the polycrystalline nature of the phosphor layers with a slight difference in the lattice dimension and level of crystallinity between the samples. XPS was used to detect the chemical bounds between the ionic species present in the phosphor layer. Additionally, ToF-ERDA accurately identify the levels of contamination originated during the ALD fabrication process. It was shown that the inclusion of Eu together with oxygen as a dopant in the CaS matrix reduces the overall crystal-field strength, which leads to blue-shifted emission by $21.2 \mathrm{~nm}$ in comparison to the CaS:Eu sample. The peak emission is found at $625.8 \mathrm{~nm}$ for CaS:EuO, whereas CaS:Eu shows the typical emission around $647 \mathrm{~nm}$. These results show that by introducing oxygen anion in the CaS:Eu thin film using ALD method, the resulting phosphor emission can be modified.

Author Contributions: Conceptualization, J.R., Z.S. and H.L.; formal analysis, J.R., J.L. and J.J.; investigation, J.R., J.L., J.J., Z.S. and H.L.; writing-original draft preparation, J.R.; writing-review and editing, J.R., Z.S. and H.L.; supervision, H.L. All authors have read and agreed to the published version of the manuscript.

Funding: The work in this paper was funded by the European Union's Horizon 2020 Research and Innovation Program under the Marie Sklodowska-Curie Grant Agreement No 76495. Z.S. and H.L. acknowledge funding from the Academy of Finland Flagship Programme, Photonics Research and Innovation (PREIN), Decision Number: 320167. Z.S. thanks the European Union's Horizon 2020 
Research and Innovation Program (820423,S2QUIP; 965124, FEMTOCHIP), the EU H2020-MSCARISE-872049 (IPN-Bio), Business Finland (ALDEL), and ERC (834742).

Institutional Review Board Statement: Not applicable.

Informed Consent Statement: Not applicable.

Data Availability Statement: Data sharing is not applicable to this article.

Acknowledgments: The authors would like to thank Saoussen Merdes and Jani Holopainen for the constructive discussions.

Conflicts of Interest: The authors declare no conflict of interest. The funders had no role in the design of the study; in the collection, analyses, or interpretation of data; in the writing of the manuscript; or in the decision to publish the results.

\section{References}

1. Puurunen, R.L. A Short History of Atomic Layer Deposition: Tuomo Suntola's Atomic Layer Epitaxy. Chem. Vap. Depos. 2014, 20, 332-344. [CrossRef]

2. Leskelä, M.; Mattinen, M.; Ritala, M. Review Article: Atomic layer deposition of optoelectronic materials. J. Vac. Sci. Technol. B 2019, 37, 030801. [CrossRef]

3. Ritala, M.; Leskela, M. Chapter 2: Atomic Layer Deposition; Academic Press: San Diego, CA, USA, 2002; ISBN 0-12-512909-2.

4. Ritala, M.; Kukli, K.; Rahtu, A.; Räisänen, P.I.; Leskelä, M.; Sajavaara, T.; Keinonen, J. Atomic Layer Deposition of Oxide Thin Films with Metal Alkoxides as Oxygen Sources. Science 2000, 288, 319-321. [CrossRef] [PubMed]

5. Van, T.T.; Chang, J.P. Controlled erbium incorporation and photoluminescence of Er-doped $\mathrm{Y}_{2} \mathrm{O}_{3}$. Appl. Phys. Lett. 2005, 87, 11907. [CrossRef]

6. Rönn, J.; Karvonen, L.; Kauppinen, C.; Perros, A.P.; Peyghambarian, N.; Lipsanen, H.; Säynätjoki, A.; Sun, Z. Atomic Layer Engineering of Er-Ion Distribution in Highly Doped Er:Al2O3 for Photoluminescence Enhancement. ACS Photon 2016, 3, 2040-2048. [CrossRef]

7. Scarafagio, M.; Tallaire, A.; Chavanne, M.-H.; Cassir, M.; Ringuedé, A.; Serrano, D.; Goldner, P.; Ferrier, A. Improving the Luminescent Properties of Atomic Layer Deposition Eu: $\mathrm{Y}_{2} \mathrm{O}_{3}$ Thin Films through Optimized Thermal Annealing. Phys. Status Solidi A 2020, 217, 1-7. [CrossRef]

8. Rönn, J.; Zhang, W.; Autere, A.; Leroux, X.; Pakarinen, L.; Alonso-Ramos, C.; Säynätjoki, A.; Lipsanen, H.; Vivien, L.; Cassan, E.; et al. Ultra-high on-chip optical gain in erbium-based hybrid slot waveguides. Nat. Commun. 2019, 10, 432. [CrossRef] [PubMed]

9. Tripathi, T.S.; Karppinen, M. Mixed-Anion Compounds: An Unexplored Playground for ALD Fabrication. Adv. Mater. Interfaces 2021, 8, 2100146. [CrossRef]

10. Cho, G.; Rhee, S.-W. Plasma Enhanced Atomic Layer Deposition of TiCxNyFilm with Various Reactive Gases. ECS J. Solid State Sci. Technol. 2014, 3, P185-P191. [CrossRef]

11. Choi, Y.-J.; Park, H.-H. A simple approach to the fabrication of fluorine-doped zinc oxide thin films by atomic layer deposition at low temperatures and an investigation into the growth mode. J. Mater. Chem. C 2014, 2, 98-108. [CrossRef]

12. Tao, J.-J.; Ma, H.-P.; Yuan, K.-P.; Gu, Y.; Lian, J.-W.; Li, X.-X.; Huang, W.; Nolan, M.; Lu, H.-L.; Zhang, D.-W. Modification of 1D TiO2 nanowires with GaOxNy by atomic layer deposition for TiO2@GaOxNy core-shell nanowires with enhanced photoelectrochemical performance. Nanoscale 2020, 12, 7159-7173. [CrossRef]

13. Closser, R.G.; Bergsman, D.S.; Bent, S.F. Molecular Layer Deposition of a Highly Stable Silicon Oxycarbide Thin Film Using an Organic Chlorosilane and Water. ACS Appl. Mater. Interfaces 2018, 10, 24266-24274. [CrossRef]

14. Rosa, J.; Deuermeier, J.; Soininen, P.J.; Bosund, M.; Zhu, Z.; Fortunato, E.; Martins, R.; Sugiyama, M.; Merdes, S. Control of Eu Oxidation State in $\mathrm{Y}_{2} \mathrm{O}_{3}-\mathrm{xSx}$ :Eu Thin-Film Phosphors Prepared by Atomic Layer Deposition: A Structural and Photoluminescence Study. Materials 2019, 13, 93. [CrossRef] [PubMed]

15. Burbano, D.C.R.; Sharma, S.K.; Dorenbos, P.; Viana, B.; Capobianco, J.A. Persistent and Photostimulated Red Emission in $\mathrm{CaS}: \mathrm{Eu}^{2+}, \mathrm{Dy}^{3+}$ Nanophosphors. Adv. Opt. Mater. 2015, 3, 551-557. [CrossRef]

16. Gao, Y.; Li, R.; Zheng, W.; Shang, X.; Wei, J.; Zhang, M.; Xu, J.; You, W.; Chen, Z.; Chen, X. Broadband NIR photostimulated luminescence nanoprobes based on $\mathrm{CaS}: \mathrm{Eu}^{2+}, \mathrm{Sm}^{3+}$ nanocrystals. Chem. Sci. 2019, 10, 5452-5460. [CrossRef] [PubMed]

17. Wang, J.; Zhu, Y.; Grimes, C.A.; Cai, Q. Multicolor lanthanide-doped CaS and SrS near-infrared stimulated luminescent nanoparticles with bright emission: Application in broad-spectrum lighting, information coding, and bio-imaging. Nanoscale 2019, 11, 12497-12501. [CrossRef]

18. Suresh, K.; Murthy, K.V.R.; Rao, A.; Poornachandra, R.N.V. Rare Earth Doped Alkali Earth Sulfide Phosphors for White-Light LEDs. ISRN Condens. Matter Phys. 2011, 2011, 392917. [CrossRef]

19. Guo, C.; Huang, D.; Su, Q. Methods to improve the fluorescence intensity of CaS:Eu ${ }^{2+}$ red-emitting phosphor for white LED. Mater. Sci. Eng. B 2006, 130, 189-193. [CrossRef] 
20. Tanaka, K.; Mikami, A.; Ogura, T.; Taniguchi, K.; Yoshida, M.; Nakajima, S. High brightness red electroluminescence in CaS:Eu thin films. Appl. Phys. Lett. 1986, 48, 1730-1732. [CrossRef]

21. Abe, Y.; Onisawa, K.-I.; Ono, Y.A.; Hanazono, M. Effects of Oxygen in CaS:Eu Active Layers on Emission Properties of Thin Film Electroluminescent Cells. Jpn. J. Appl. Phys. 1990, 29, 1495-1498. [CrossRef]

22. Poelman, D.; Vercaemst, R.; van Meirhaeghe, R.; Laflère, W.; Cardon, F. Influence of the growth conditions on the properties of CaS:Eu electroluminescent thin films. J. Lumin 1997, 75, 175-181. [CrossRef]

23. Poelman, D.; van Haecke, J.E.; Smet, P. Advances in sulfide phosphors for displays and lighting. J. Mater. Sci. Mater. Electron. 2009, 20, 134-138. [CrossRef]

24. Dorenbos, P. Energy of the first $4 \mathrm{f} 7 \rightarrow 4 \mathrm{f} 65 \mathrm{~d}$ transition of $\mathrm{Eu}^{2+}$ in inorganic compounds. J. Lumin. 2003, 104, 239-260. [CrossRef]

25. Sung, H.J.; Cho, Y.S.; Huh, Y.; Do, Y. Preparation, Characterization and Photoluminescence Properties of Ca1-xSrxS:Eu Redemitting Phosphors for a White LED. Bull. Korean Chem. Soc. 2007, 28, 1280-1284. [CrossRef]

26. Lin, J.; Huang, Y.; Mi, J.; Zhang, X.; Lu, Z.; Xu, X.; Fan, Y.; Zou, J.; Tang, C. BN-coated Ca1-xSrxS:Eu solid-solution nanowires with tunable red light emission. Nanotechnology 2013, 24, 405701. [CrossRef]

27. Sun, B.; Yi, G.; Chen, D.; Zhou, Y.; Cheng, J. Synthesis and characterization of strongly fluorescent europium-doped calcium sulfide nanoparticles. J. Mater. Chem. 2002, 12, 1194-1198. [CrossRef]

28. Rosa, J.; Heikkilä, M.; Sirkiä, M.; Merdes, S. Red $\mathrm{Y}_{2} \mathrm{O}_{3}$ :Eu-Based Electroluminescent Device Prepared by Atomic Layer Deposition for Transparent Display Applications. Materials 2021, 14, 1505. [CrossRef] [PubMed]

29. Getz, M.N.; Hansen, P.-A.; Fjellvåg, H.; Nilsen, O. Luminescent properties of europium titanium phosphate thin films deposited by atomic layer deposition. RSC Adv. 2017, 7, 8051-8059. [CrossRef]

30. Rönn, J.; Zhang, J.; Zhang, W.; Tu, Z.; Matikainen, A.; le Roux, X.; Durán-Valdeiglesias, E.; Vulliet, N.; Boeuf, F.; Ramos, C.A.; et al. Erbium-doped hybrid waveguide amplifiers with net optical gain on fully industrial $300 \mathrm{~mm}$ silicon nitride photonic platform. Opt. Express 2020, 28, 27919. [CrossRef]

31. Sicre, J.E.; Dubois, J.T.; Eisentraut, K.J.; Sievers, R.E. Volatile lanthanide chelates. II. Vapor pressures, heats of vaporization, and heats of sublimation. J. Am. Chem. Soc. 1969, 91, 3476-3481. [CrossRef]

32. Wyckoff, R.W.G. Crystal Structures, 2nd ed.; Interscience Publishers: New York, NY, USA, 1963.

33. Naumkin, A.V.; Kraut-Vass, A.; Gaarenstroom, S.W.; Powell, C.J. NIST X-ray Photoelectron Spectroscopy Database, NIST Standard Reference Database Number 20. Available online: https:/ / srdata.nist.gov/xps/citation.aspx (accessed on 2 September 2021).

34. Liu, W.-Q.; Wu, D.; Chang, H.; Duan, R.-X.; Wu, W.-J.; Amu, G.; Chao, K.-F.; Bao, F.-Q.; Tegus, O. The Enhanced Red Emission and Improved Thermal Stability of CaAlSiN3:Eu ${ }^{2+}$ Phosphors by Using Nano-EuB6 as Raw Material. Nanomaterials 2018, 8, 66. [CrossRef] [PubMed]

35. Nyenge, R.; Swart, H.; Ntwaeaborwa, O. Luminescent properties, intensity degradation and X-ray photoelectron spectroscopy analysis of CaS:Eu ${ }^{2+}$ powder. Opt. Mater. 2015, 40, 68-75. [CrossRef]

36. Dezelah, C.L.; Myllymäki, P.; Päiväsaari, J.; Arstila, K.; Niinistö, L.; Winter, C.H. The growth of $\mathrm{Er}_{x} \mathrm{Ga}_{2-\mathrm{x}} \mathrm{O}_{3}$ films by atomic layer deposition from two different precursor systems. J. Mater. Chem. 2007, 17, 1308-1315. [CrossRef] 